\title{
Factor Decomposition on Energy Cost Change of Freight Hub Based on SDA
}

\author{
Li Xiao ${ }^{1, a^{*}}$, Liu Bin ${ }^{2, b}$ and Liu Li ${ }^{3, c}$ \\ ${ }^{1}$ Research Institute Of Highway Ministry Of Transport China \\ ${ }^{2}$ Research Institute Of Highway Ministry Of Transport China \\ ${ }^{3}$ Research Institute Of Highway Ministry Of Transport China

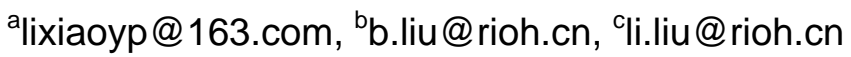

Keywords: Factor decomposition; SDA; Energy consumption

\begin{abstract}
The paper construct the factor decomposition model based on SDA, with the idea of jointly created and equally distributed. The model is used to analysis the energy cost change of freight hub for example. Through the analysis and calculation of the energy consumption data of freight hub, the conclusion is shown: The unit cost decline is the common contribution by cost effectiveness and energy structure. In the cost effectiveness, natural gas played a positive role for two years. In the energy structure, gasoline makes the most change. For the energy consumption cost control of freight hub, extensive promotion of natural gas vehicle and large vehicle are very effective measures.
\end{abstract}

\section{Introduction}

With the rapid development of economic in China, highway freight transport growth fast. By the end of 2015, 31.5 billion tons of freight was completed by commercial vehicles, highway freight turnover was 5.795572 trillion ton-km. Growth of $1.2 \%$ and $1.2 \%$ respectively over the previous year. Along with the increasing of the freight transport demand, the role of freight hub become more and more important. But now, it still has the problem with high energy consumption, high cost and low energy efficiency. Energy consumption cost is an important part of cost control in. Hao Ruibin analysis the spatial and temporal variations of energy consumption intensity based on the SDA ${ }^{[1]}$. Xu Ting analysis the cost control about the number of devices in cargo terminal ${ }^{[2]}$. Linda $\mathrm{K}$ put forward the influence of cost control about transportation in freight hub ${ }^{[3]}$. But the analyzation on energy consumption cost is still imperfection.

\section{Factor Decomposition Model}

SDA (Structure Decomposition Analysis) is a mainstream analysis model in input and output field. This decomposes the variable in economic system into the sum of each independent factor. It can be used to test the contribution of each independent variable. The paper constructs the factor decomposition model based on the SDA.

The calculation of the unit energy consumption cost is shown in formula (1):

$$
e=\frac{G}{E}
$$

In formula (1), $e$ is the unit energy consumption cost; $G$ is the energy consumption cost; $E$ is the total energy consumption.

Energy consumption of freight hub mainly includes electricity, gas, coal, gasoline and diesel. Kinds of energy consumption decomposition model are shown in formula (2):

$$
e=\frac{G}{E}=\sum_{i}^{n} G_{i} / E=\sum_{i}^{n} G_{i} / E_{i} \times E_{i} / E=\sum_{i}^{n} e_{i} S_{i}
$$

In formula (2), $G_{i}$ is the consumption cost of energy $i ; E_{i}$ is the consumption of energy $i ; e_{i}$ is the unit consumption cost of energy $i ; s_{i}$ is consumption accounted of energy $i$. 
As shown in formula (2), the influence factors about energy cost can be decomposed into two parts: one is cost effectiveness, the other is energy structure. Changes in the cost of energy from 0 to period are shown in formula (3):

$$
\Delta e=\sum_{i}^{n}\left(e_{i t} s_{i t}-e_{i 0} s_{i 0}\right)=\sum_{i}^{n}\left[e_{i 0}\left(s_{i t}-s_{i 0}\right)+s_{i 0}\left(e_{i t}-e_{i 0}\right)+\left(e_{i t}-e_{i 0}\right)\left(s_{i t}-s_{i 0}\right)\right]
$$

In formula (3), $\Delta e$ is the variation of energy consumption; $\left(e_{i t}-e_{i 0}\right)\left(s_{i t}-s_{i 0}\right)$ describes the joint action of the cost effectiveness and energy structure. J.W.Sun puts forward the idea of jointly created and equally distributed ${ }^{[4][5]}$. Based on the methods, The factor decomposition model is shown in formula (4):

$$
\begin{aligned}
& \Delta e_{s t r}=\sum_{i}^{n}\left(s_{i t}-s_{i 0}\right) e_{i 0}+0.5 \sum_{i}^{n}\left(e_{i t}-e_{i 0}\right)\left(s_{i t}-s_{i 0}\right) \\
& \Delta e_{e f f}=\sum_{i}^{n}\left(e_{i t}-e_{i 0}\right) s_{i 0}+0.5 \sum_{i}^{n}\left(e_{i t}-e_{i 0}\right)\left(s_{i t}-s_{i 0}\right) \\
& \Delta e=\Delta e_{\text {str }}+\Delta e_{e f f} i
\end{aligned}
$$

In formula(4), $\Delta e_{\text {str }}$ is the variation of energy structure; $\Delta e_{\text {eff }}$ is the variation of cost effectiveness; the calculation of the energy structure and the cost effectiveness in period $t$ of energy $i$ was shown in formula (5):

$$
\begin{aligned}
& \Delta e_{i s t r}=\left(s_{i t}-s_{i 0}\right) e_{i 0}+0.5\left(e_{i t}-e_{i 0}\right)\left(s_{i t}-s_{i 0}\right) \\
& \Delta e_{i e f f}=\left(e_{i t}-e_{i 0}\right) s_{i 0}+0.5\left(e_{i t}-e_{i 0}\right)\left(s_{i t}-s_{i 0}\right)
\end{aligned}
$$

\section{Energy Consumption of Freight Hub}

Energy consumption of freight hub mainly includes electricity, gas, coal, gasoline and diesel. Purpose of all kinds energy is shown in Figure 1.

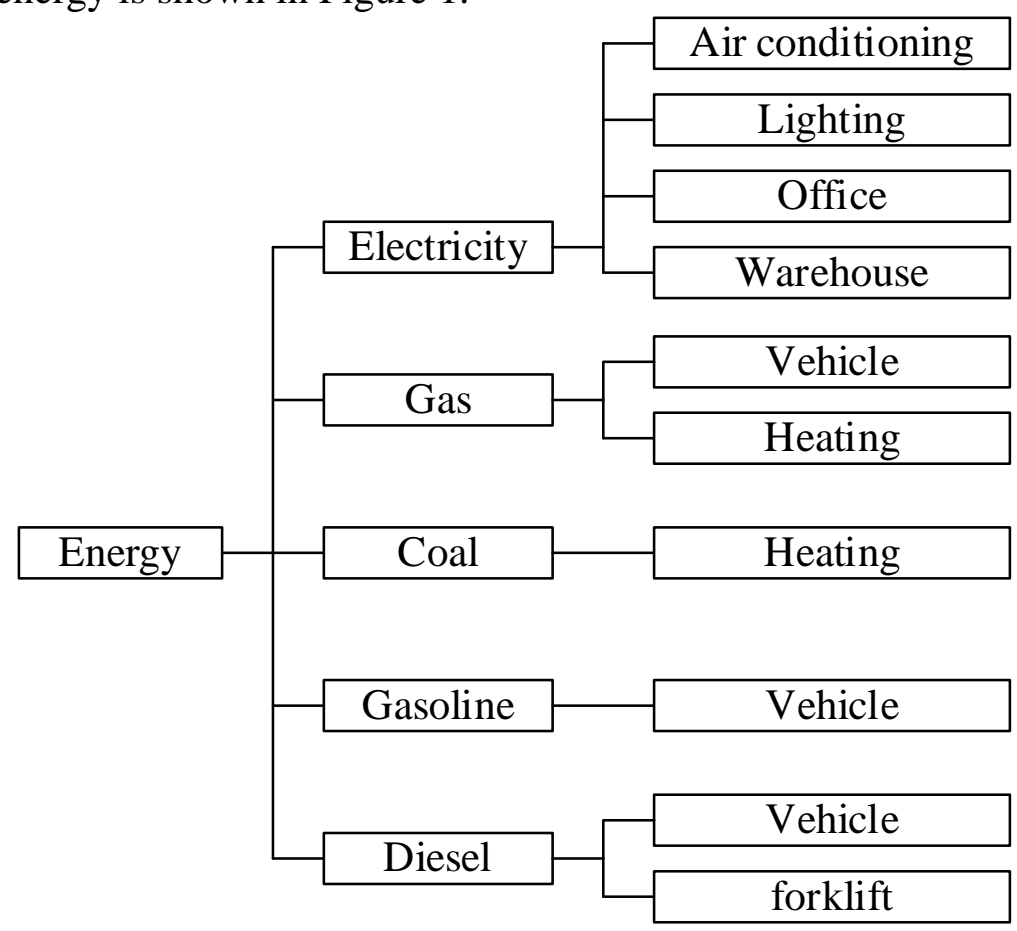

Figure 1 Purpose of all kinds energy

The paper takes a freight hub for example. The energy consumption from 2013 to 2015 is shown in Table 1. 
Table 1 The energy consumption from 2013 to 2015

\begin{tabular}{ccccccc}
\hline \multirow{2}{*}{ Year } & $\begin{array}{c}\text { Energy } \\
\text { category }\end{array}$ & Unit & $\begin{array}{c}\text { actual } \\
\text { consumption }\end{array}$ & $\begin{array}{c}\text { Standard } \\
\text { coal[tce] }\end{array}$ & $\begin{array}{c}\text { Accounted for } \\
\text { energy }\end{array}$ & $\begin{array}{c}\text { Cost[Ten thousand } \\
\text { yuan] }\end{array}$ \\
\hline \multirow{4}{*}{2013} & Electricity & Kwh & 5559026.7 & 683.2 & $15.16 \%$ & 455.62 \\
& Gas & $\mathrm{m}^{3}$ & 230837.6 & 307.01 & $6.81 \%$ & 50.11 \\
& Coal & $\mathrm{GJ}$ & 1826.18 & 62.27 & $1.38 \%$ & 12.68 \\
& Gasoline & $\mathrm{T}$ & 503.91 & 741.46 & $16.45 \%$ & 398.67 \\
& Diesel & $\mathrm{T}$ & 1861.33 & 2712.15 & $60.19 \%$ & 1117.47 \\
& Sum & $\mathrm{tce}$ & - & $\mathbf{4 5 0 6 . 0 9}$ & $\mathbf{1 0 0 \%}$ & $\mathbf{2 0 3 4 . 5 5}$ \\
& Electricity & $\mathrm{Kwh}$ & 5949052.5 & 731.14 & $17.85 \%$ & 473.08 \\
& Gas & $\mathrm{m}^{3}$ & 296936.8 & 394.93 & $9.64 \%$ & 63.28 \\
& Coal & $\mathrm{GJ}$ & 1993.38 & 67.97 & $1.66 \%$ & 16.61 \\
& Gasoline & $\mathrm{T}$ & 370.85 & 545.66 & $13.32 \%$ & 255.62 \\
& Diesel & $\mathrm{T}$ & 1617.9 & 2357.44 & $57.54 \%$ & 949.92 \\
& Sum & $\mathrm{tce}$ & - & $\mathbf{4 0 9 7 . 1 4}$ & $\mathbf{1 0 0 \%}$ & $\mathbf{1 7 5 8 . 5 1}$ \\
& Electricity & $\mathrm{Kwh}$ & 4472368 & 549.65 & $11.66 \%$ & 364.07 \\
& Gas & $\mathrm{m}$ & 379300.65 & 460.58 & $9.77 \%$ & 68.89 \\
& Coal & $\mathrm{GJ}$ & 2119.06 & 72.26 & $1.53 \%$ & 11.77 \\
& Gasoline & $\mathrm{T}$ & 407.5 & 599.59 & $12.72 \%$ & 320.42 \\
& Diesel & $\mathrm{T}$ & 2081.41 & 3032.83 & $64.32 \%$ & 1085.06 \\
& Sum & tce & - & $\mathbf{4 7 1 4 . 9 1}$ & $\mathbf{1 0 0 \%}$ & $\mathbf{1 8 5 0 . 2 1}$ \\
\hline
\end{tabular}

As shown in Table 1, In terms of total energy consumption, 2014 is the lowest energy consumption and the cost. The reason is freight hub slumped in 2014. The unit cost decline year by year, the reason is more and more efficient energy-using products and energy saving technology is used widely. The variation of energy consumption and the cost is shown in Figure 2.

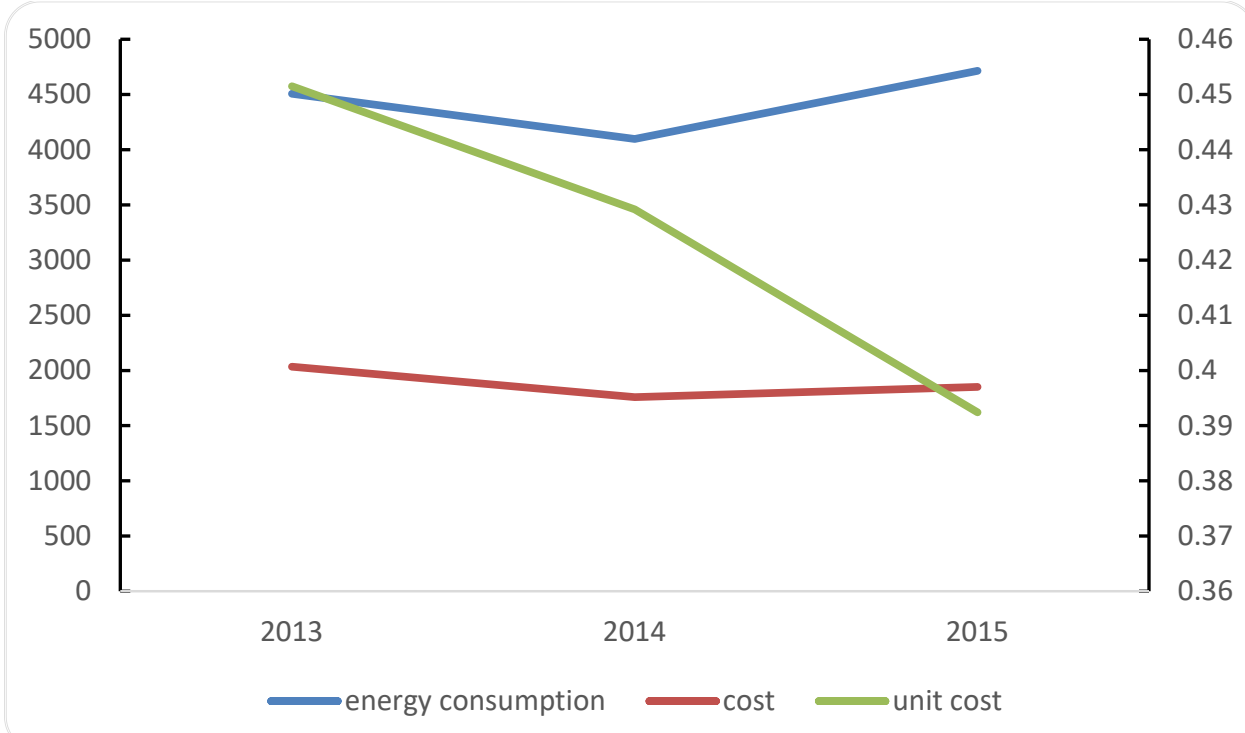

Figure 2 The variation of energy consumption and the cost

In terms of Energy category, the proportion of all kinds of energy remained stable basically.

Because the freight and goods loading is the main business, diesel consumption used by vehicles and forklift occupy the largest proportion. From 2014, gas consumption increase rapidly, the reason is to response the emission reduction requirements of nation, more natural gas vehicle is used. The proportion of all kinds of energy is shown in Figure 3. 


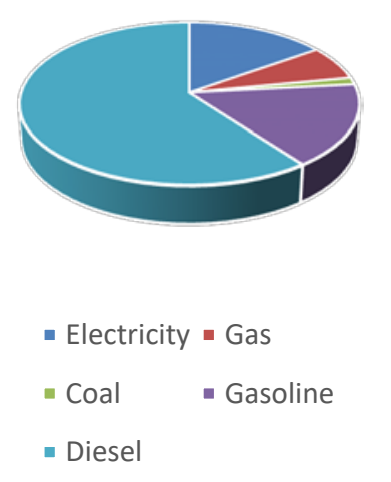

2013

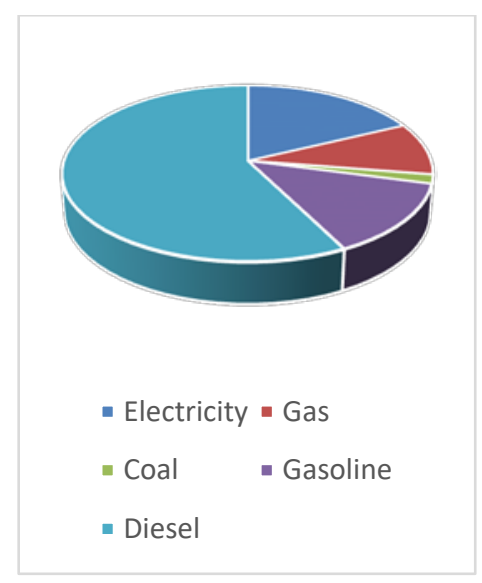

2014

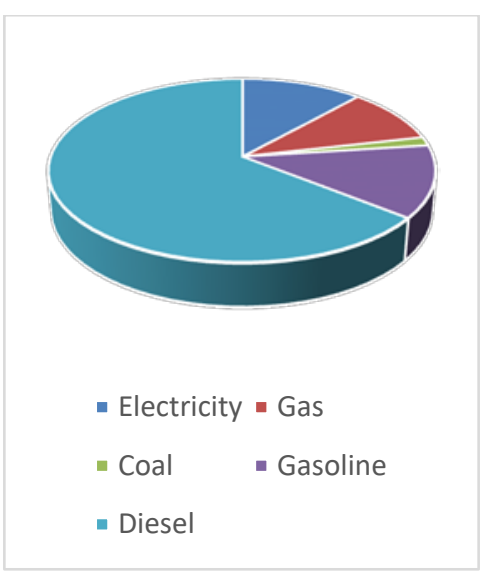

2015

Figure 3 The proportion of all kinds of energy

\section{Calculation of SDA Model}

Based on the SDA model, Paper carry on the factor decomposition on energy cost change of freight hub. The calculation results of cost effectiveness and energy structure is shown in Table2.

Table 2 The calculation result of cost effectiveness and energy structure

\begin{tabular}{ccccccc}
\hline \multirow{2}{*}{ Year } & \multicolumn{2}{c}{ Electricity } & \multicolumn{2}{c}{ Gas } & \multicolumn{2}{c}{ Coal } \\
& cost & structure & cost & structure & cost & structure \\
\hline 2013 & 0.6669 & 0.15 & 0.1632 & 0.07 & 0.2036 & 0.01 \\
2014 & 0.6470 & 0.18 & 0.1602 & 0.10 & 0.2444 & 0.02 \\
2015 & 0.6624 & 0.12 & 0.1469 & 0.10 & 0.1629 & 0.01 \\
& & Gasoline & & & Diesel & \\
year & cost & \multicolumn{2}{c}{ structure } & cost & & structure \\
2013 & 0.5377 & & 0.17 & 0.4120 & & 0.60 \\
2014 & 0.4685 & & 0.12 & 0.4029 & & 0.58 \\
2015 & 0.5344 & & 0.13 & 0.3578 & & 0.64 \\
\hline
\end{tabular}

Use the calculation results which is shown in Table 2. The variation of cost effectiveness and energy structure can be decomposed. The variation of cost effectiveness is shown in Table 3; The variation of energy structure is shown in Table 4.

Table 3 The variation of cost effectiveness

\begin{tabular}{cccccc}
\hline Year & Electricity & Gas & Coal & Gasoline & Diesel \\
\hline $2013-2014$ & -0.0033 & -0.0003 & 0.0006 & -0.0100 & -0.0053 \\
$2014-2015$ & 0.0023 & -0.0013 & -0.0012 & 0.0082 & -0.0275 \\
$2013-2015$ & -0.0006 & -0.0014 & -0.0004 & -0.0005 & -0.0336 \\
\hline
\end{tabular}

Table 4 The variation of energy structure

\begin{tabular}{cccccc}
\hline Year & Electricity & Gas & Coal & Gasoline & Diesel \\
\hline $2013-2014$ & 0.0197 & 0.0049 & 0.0022 & -0.0252 & -0.0081 \\
$2014-2015$ & -0.0393 & 0.0000 & -0.0020 & 0.0050 & 0.0228 \\
$2013-2015$ & -0.0199 & 0.0047 & 0.0000 & -0.0214 & 0.0000 \\
\hline
\end{tabular}

Based on the Table 3 and Table 4, The factor decomposition on energy cost change of freight hub is shown in Table 5. 
Table 5 The factor decomposition on energy cost change of freight hub

\begin{tabular}{ccc}
\hline Year & Cost effectiveness & Energy structure \\
\hline $2013-2014$ & -0.0183 & -0.0065 \\
$2014-2015$ & -0.0195 & -0.0135 \\
$2013-2015$ & -0.0365 & -0.0367 \\
\hline
\end{tabular}

As shown in table 3, table 4 and table 5 , The unit cost decline is the common contribution by cost effectiveness and energy structure. In the cost effectiveness, diesel makes the most change, natural gas played a positive role for two years. It because the price of diesel has a sharp fall in 2015, and natural gas has a lower cost, because of more natural gas vehicle was used in 2014 and 2015, the overall energy cost decreased. In the energy structure, gasoline makes the most change, because of larger vehicles is used, the consumption of gasoline decreased, that plays a positive role about the unit energy cost.

\section{Conclusion}

The variation of energy cost of the freight hub has a characteristic of time regularity. the unit energy cost decline year by year. During 2013 to 2015, the proportion of unit energy cost decline $13 \%$,from 4515 yuan/tce to 3924 yuan/tce. It means the adjustment of energy structure, choose low energy cost and the measures of energy-saving technology has obtained the obvious effect.

The unit cost decline is the common contribution by cost effectiveness and energy structure. Each of the contribution rate are $50 \%$. It means the cost effectiveness and energy structure are equally important for the energy cost control of freight hub. Except the objective factors of diesel prices decrease, a large amount of natural gas vehicle applications played an important role. Natural gas is a kind of low cost, clean energy which can be used in vehicle. It should be promoted widely. In addition, large diesel vehicles are used to replace gasoline vehicle. It is a very effective measures to reduce the unit energy cost in the aspect of energy structure.

\section{References}

[1]Hao Ruibin. Changes of Energy Consumption Intensity and Analysis on Influential Factors in Hebei Province [J]. Journal of Tangshan Teachers College.2013(5):146-149

[2] Xu Ting. Research on the number of device in cargo terminal based on the cost optimization[J]. Highways and Automotive applications. 2013(1):84-86

[3] Linda K. Natick. Two-echelon Inventory Allocation and Distribution Center Location Analysis [J]. Transportation Research.2007, 37(6):425-441.

[4] Sun J W, Accounting for energy use in China, 1980-1994[J]. energy, 1998,23(10):853-849.

[5] Sun J W, Changes in energy consumption and energy intensity: A complete decomposition model [J]. Energy Economics, 1998,20(1):85-100. 